\title{
Randomized trial comparing partial versus complete chordal-sparing mitral valve replacement: Effects on left ventricular volume and function
}

Kwok L. Yun, MD

Colleen F. Sintek, MD

D. Craig Miller, $M D^{a}$

Thomas A. Pfeffer, MD

Gary S. Kochamba, MD

Siavosh Khonsari, MD

Michael R. Zile, MD ${ }^{\mathrm{b}}$

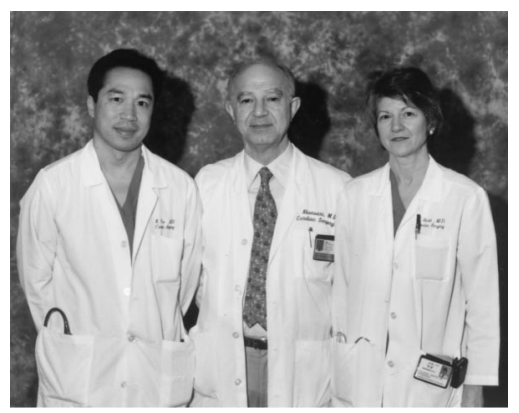

Yun, Khonsari, Sintek (left to right)
From the Department of Cardiac Surgery, Kaiser Permanente Medical Center, Los Angeles, Calif, Department of Cardiothoracic Surgery, ${ }^{a}$ Stanford University, Stanford, Calif, and Division of Cardiology, ${ }^{\mathrm{b}}$ Medical University of South Carolina, Charleston, SC

Supported in part by an unrestricted grant from St Jude Medical, Inc, St Paul, Minn.

Read at the Twenty-seventh Annual Meeting of The Western Thoracic Surgical Association, San Diego, Calif, June 20-23, 2001

Received for publication July 18,2001 ; revisions requested Aug 28, 2001; revisions received Sept 26, 2001; accepted for publication Oct 9, 2001.

Address for reprints: Kwok L. Yun, MD, Department of Cardiac Surgery, Southern California Permanente Medical Group, 1526 North Edgemont St, 3rd Floor, Los Angeles, CA 90027 (E-mail: Kwok.L. Yun@kp.org).

J Thorac Cardiovasc Surg 2002;123:707-14

Copyright () 2002 by The American Association for Thoracic Surgery

$0022-5223 / 2002 \$ 35.00+0 \quad \mathbf{1 2 / 6 / 1 2 1 0 4 8}$

doi: $10.1067 / \mathrm{mtc} .2002 .121048$
Objective: The merits of retaining the subvalvular apparatus during mitral valve replacement for chronic mitral regurgitation have been demonstrated in numerous retrospective clinical investigations but not in a randomized study. In this report we analyzed the early and late effects of complete versus partial chordal preservation on left ventricular mechanics.

Methods: Forty-seven patients undergoing isolated surgical correction of mitral insufficiency were prospectively randomized to either total or partial chordal-sparing mitral valve replacement. Complete data from 36 patients were available for analysis. Of these individuals, 15 had preservation of the posterior leaflet only (P-MVR group), and 21 had complete preservation of all chordal structures (C-MVR group). Echocardiography was performed preoperatively, at the time of discharge, and after 1 year to determine dimensions, wall stress, left ventricular mass, and ejection function.

Results: End-diastolic volume decreased in both groups initially but continued to decline only in the C-MVR cohort. Similarly, although end-systolic volume decreased over time with total chordal preservation, no notable changes were observed in the P-MVR group. In the C-MVR group, end-systolic stress decreased initially but rose slightly by 1 year. In contrast, end-systolic stress remained unchanged at discharge in the P-MVR group and increased at 1 year. In terms of systolic performance, ejection fraction declined after surgical intervention with partial chordal-sparing techniques and did not improve by 1 year. Ejection fraction returned to the preoperative level after an initial decrease in the C-MVR group. Finally, left ventricular mass was reduced in the C-MVR cohort versus no change in the P-MVR group.

Conclusion: Complete retention of the mitral subvalvular apparatus during mitral valve replacement confers a significant early advantage by reducing left ventricular chamber size and systolic afterload compared with partial chordal preservation. Furthermore, left ventricular ejection performance continues to improve over time, probably because of more favorable left ventricular remodeling.

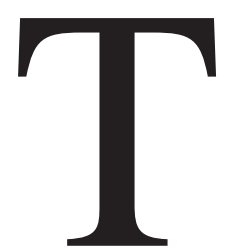
he early ${ }^{1-3}$ and late ${ }^{4-6}$ hemodynamic benefits of preserving the mitral subvalvular apparatus during mitral valve replacement (MVR) have been demonstrated in several studies. Although some investigators ${ }^{4,7,8}$ have retrospectively examined the issue of complete versus partial chordal preservation, this question has not been addressed rigorously in the clinical setting with extended follow-up. As a result, many surgeons continue to retain only the posterior leaflet chordae tendineae 
because of concerns over greater technical complexity, longer operating time, potential interference with mechanical valve leaflet motion, need to undersize the mitral prosthesis, and the possibility of creating left ventricular (LV) outflow tract obstruction. ${ }^{9}$ In a recent preliminary analysis ${ }^{10}$ of the first 19 patients in this larger prospective, randomized trial, we reported superior LV systolic performance of complete (bileaflet) chordal sparing during MVR compared with partial (posterior leaflet only) chordal preservation for isolated mitral regurgitation early postoperatively. In this study the complete data set, along with 1-year follow-up echocardiographic results, are presented.

\section{Methods}

Between March 1996 and April 1998, 47 patients undergoing MVR for chronic mitral regurgitation at Southern California Kaiser Permanente Medical Center in Los Angeles were prospectively randomized to either partial (posterior leaflet) or complete (anterior and posterior) chordal preservation groups. Originally, the study was designed for 50 patients. However, because of time and resource constraints, a termination date was set at the end of a 2-year period. As a result, only 47 patients were enrolled in the study. Of these patients, 22 underwent partial (P-MVR group) and 25 had complete (C-MVR group) preservation of the mitral subvalvular apparatus. All valves were deemed to be nonreparable at the time of operation by the surgeon. Those patients with evidence of coronary artery disease or substantial mitral stenosis (mean transvalvular gradient $>5 \mathrm{~mm} \mathrm{Hg}$ ) were excluded. Informed consent was obtained from all patients, and the protocol was approved by our institution's investigational review board.

\section{Surgical Techniques}

Standard moderate hypothermic (approximately $28^{\circ} \mathrm{C}-32^{\circ} \mathrm{C}$ ) cardiopulmonary bypass was used. Myocardial protection consisted of intermittent antegrade, retrograde, or both cold hyperkalemic cardioplegia. In patients randomized to the partial chordal-sparing technique, the anterior leaflet, along with its attached chordae tendineae, was excised. The posterior leaflet and its chordal attachments were preserved. If the posterior leaflet was excessively redundant or the chordae tendineae were elongated, the leaflet was imbricated into the mitral anulus with the valve sutures. In those patients randomized to complete chordal preservation, the entire subvalvular apparatus was preserved in an anatomic fashion, as described by Sintek and associates. ${ }^{11}$ In brief, the anterior leaflet was detached $3 \mathrm{~mm}$ from the anulus, and a central ellipse-shape portion was excised, leaving a 5- to 10-mm rim of leaflet-free edge attached to the primary (first order or marginal) chordae tendineae. This strip of leaflet was then reattached to the anulus in the corresponding location with the valve sutures (Khonsari II technique). Alternatively, if the anterior leaflet was excessively redundant, it was divided into 2 to 4 segments, which were then resuspended in a normal anatomic position with the valve sutures (Khonsari I technique).

\section{Echocardiographic Studies and Measurements}

Two-dimensional, M-mode, and color-flow Doppler transthoracic echocardiography with standard acoustic windows were performed in all patients just before operation, at the time of hospital discharge, and after 1 year. All study results were read by one observer (M.R.Z.) in a blinded fashion on completion of the investigation. Mean values for each measurement were derived from 3 consecutive heart beats in patients in sinus rhythm and from 5 beats in those in atrial fibrillation. End-diastole was defined as the onset of the electrocardiographic Q wave, and end-systole was defined as the time of minimum LV dimension. Instantaneous LV volume (V) was calculated as follows:

$$
\mathrm{V}=\pi / 6 \mathrm{D}^{2} \mathrm{~L},
$$

where $\mathrm{D}$ is the LV minor-axis dimension acquired from the shortaxis view, and $\mathrm{L}$ is the long-axis dimension acquired from the apical 4-chamber view. Ejection fraction (EF) was computed by using LV end-diastolic volume (EDV) and end-systolic volume (ESV). Similarly, long-axis fractional shortening (LAFS) was determined by using end-diastolic and end-systolic long LV-axis dimensions. Midwall circumferential end-systolic LV stress (ESS), a clinically useful estimate of LV afterload, was calculated by using Mirsky's formula ${ }^{12}$ for a prolate ellipsoid as follows:

$$
\mathrm{ESS}=\mathrm{Pb} / \mathrm{h}\left[1-(\mathrm{h} /[2 \mathrm{~b}])-\left(\mathrm{b}^{2} /\left[2 \mathrm{a}^{2}\right]\right) \cdot 1.332 \mathrm{kdyne} / \mathrm{cm}^{2},\right.
$$

where $\mathrm{P}$ is 0.98 times the mean arterial (cuff) pressure plus $11 \mathrm{~mm}$ $\mathrm{Hg},{ }^{7} \mathrm{~h}$ is the end-systolic wall thickness, $\mathrm{b}$ is the end-systolic semiminor axis $([D+h] / 2)$, and $a$ is the end-systolic semimajor axis $([\mathrm{L}+\mathrm{h}] / 2)$. Mean arterial cuff pressure was defined as follows:

$$
\text { [Systolic blood pressure }+2 \text { (Diastolic blood pressure)]/3. }
$$

The ESS/ESV ratio was also computed as a relatively less loadsensitive index of LV systolic performance. ${ }^{13}$ Finally, LV mass (LVM) was estimated by the following formula ${ }^{14}$ :

$$
\mathrm{LVM}=1.04 \cdot\left([\mathrm{D}+2 \mathrm{~h}]^{3}-\mathrm{D}^{3}\right)-14 .
$$

\section{Statistical Analysis}

All data are expressed as means \pm SD unless specified otherwise. Demographic characteristics of each surgical group were compared with the Fisher exact test for categoric variables and the unpaired $t$ test for continuous variables. Repeated-measures analysis of variance was used to assess the influence of time (preoperatively vs postoperatively vs 1 year) and type of procedure (P-MVR vs C-MVR) on all echocardiographic derived parameters. If a significant $F$ value resulted, the Scheffe test was performed to determine which individual differences may be important. The differences between the 2 groups in the changes of the discharge and 1-year values from baseline were assessed by using the unpaired $t$ test.

\section{Results}

Two patients were lost to follow-up (one in each group). Two patients in the P-MVR group died 9 days after the operation as a result of deteriorating hemodynamics and multiorgan system failure. Three 1-year follow-up echocardiographic studies in the P-MVR group, performed at their respective satellite facilities, were of such poor quality that accurate measurements were not possible. Furthermore, it was predetermined at the initiation of the study that patients 
with preoperative end-systolic diameters of greater than 50 $\mathrm{mm}$ were to be excluded from analysis because a poor outcome has previously been demonstrated in those undergoing MVR with such LV decompensation, despite chordal preservation. ${ }^{15-19}$ Four patients ( 3 in the C-MVR and 1 in the P-MVR group) fell into this category. Consequently, data from 36 patients (21 in the C-MVR and 15 in the P-MVR group) were included in the final analysis.

Selected preoperative patient characteristics according to operative procedure group are summarized in Table 1. Most patients had myxomatous degenerative changes of the mitral leaflets and subvalvular apparatus. Although there was a greater percentage of male patients in the C-MVR cohort, no differences were noted in terms of age or preoperative New York Heart Association classification. Intraoperatively, 26 St Jude (St Jude Medical, Inc) bileaflet mechanical prostheses (13 in each group) and 10 Hancock (Medtronic, Inc) porcine valves ( 8 in the C-MVR and 2 in the P-MVR group) were inserted $(P=.21)$.

The echocardiographically measured EDV, ESV, ESS, $\mathrm{EF}$, LAFS, and LVM values, as well as the calculated ESS/ESV ratios, are shown in Table 2. Preoperatively, patients in the C-MVR group had larger hearts, greater ESS, and lower ejection performance. Two-way repeated-measures analysis of variance demonstrated that although EDV decreased from the preoperative level at the time of discharge in both groups, it fell further only in the C-MVR cohort after 1 year. Similarly, although ESV continued to decline over time in those with total chordal preservation, no notable changes were observed in the P-MVR group. In the C-MVR group ESS decreased initially but rose slightly at 1 year. In contrast, ESS remained unchanged at the discharge study in the P-MVR patients and increased by 1 year. In terms of ejection performance, both EF and LAFS decreased after operation with partial chordal preservation and did not improve by 1 year. On the other hand, EF and LAFS in the C-MVR cohort returned to the preoperative level after initial declines. As a relatively load-insensitive index of systolic performance, the ESS/ESV ratio markedly improved after 1 year in the C-MVR group. In the P-MVR patients the 1-year value of ESS/ESV trended back toward the preoperative level after a significant decline at discharge. Finally, LVM was reduced in the C-MVR cohort versus no change in those in the P-MVR group. The percentage changes at discharge and at 1 year from preoperative levels are depicted in Figures 1 and 2, respectively.

Of the 4 patients with preoperative end-systolic diameters greater than $50 \mathrm{~mm}(1$ in the P-MVR and 3 in the C-MVR group), only one had reductions in EDV, ESV, ESS, and LVM and improvement in EF, LAFS, and ESS/ ESV ratio after 1 year. This individual had complete preservation of the subvalvular apparatus. The remaining 3 patients had worsening LV mechanics with time. The one
TABLE 1. Selected patient characteristics according to procedure type

\begin{tabular}{lccc}
\hline Characteristics & P-MVR $(\mathbf{n}=\mathbf{1 5})$ & C-MVR $(\mathbf{n}=\mathbf{2 1})$ & $\boldsymbol{P}$ value \\
\hline Age & $59 \pm 11$ & $56 \pm 13$ & .48 \\
Male sex & 4 & 15 & .02 \\
NYHA functional class & $2.5 \pm 0.8$ & $2.6 \pm 0.9$ & .96 \\
Cause & 13 & & .33 \\
$\quad$ Myxomatous & 2 & 18 & \\
Rheumatic & 0 & 1 & \\
Endocarditis & & 2 & \\
\hline
\end{tabular}

Values are means \pm 1 SD.

NYHA, New York Heart Association.

patient who received preservation of the posterior chords had a sudden death event shortly after the 1-year echocardiographic study, probably as a result of arrhythmia and end-stage heart failure. The percentage changes of the echocardiographic parameters after 1 year from baseline in these 4 patients are summarized in Figure 3.

\section{Discussion}

Although the merits of chordal preservation during MVR have been examined in numerous clinical studies, the results have not been uniform because of the retrospective nature of the investigations, heterogeneous patient populations, mixed valvular pathology, and the absence of controlled, randomized trials. Furthermore, despite laboratory findings supporting the contribution of all chordal structures to LV systolic function in the normal canine heart, ${ }^{20-22}$ the importance of retaining the anterior subvalvular apparatus in addition to the posterior leaflet in patients with chronic mitral insufficiency remains controversial. Therefore this study was undertaken to determine the immediate and delayed effects of complete versus partial chordal-sparing MVR.

Consistent with reports of other investigators, , ,4,8,15,18,23-27 the correction of the volume overload caused by chronic mitral insufficiency decreased EDV postoperatively independent of the operative technique, although there was a greater reduction when all chords were retained. However, only in the C-MVR cohort did EDV decline further after 1 year. Similarly, ESV decreased early after complete chordal-sparing MVR, which is concordant with previous observations ${ }^{1,2,4,7,8,28}$ and continued to decrease with time. In contrast, ESV remained relatively unchanged in the P-MVR group. This discordant change in ESV is explained by the interdependence of the changes in ESS (consequently ESV), EF, and EDV after MVR. According to the mathematic model validated by Goldfine and colleagues, ${ }^{29}$ for any EDV, a lower EF is associated with a larger ESV and, by virtue of the Laplace relation, a higher ESS. Therefore the greater reduction in $\mathrm{EF}$ in patients with partial chordal preservation can result in an increase in ESS and ESV despite a decrease in EDV. In contrast, because of a relatively higher postoperative $\mathrm{EF}$ and a greater decline in EDV, it was not unex- 
TABLE 2. Echocardiographic measurements according to procedure type

\begin{tabular}{|c|c|c|c|c|c|}
\hline Parameter & Preoperative & Discharge & 1 year & $\begin{array}{c}P \text { value } \\
\text { (time) }\end{array}$ & $\begin{array}{c}P \text { value } \\
\text { (time } \times \text { group) }\end{array}$ \\
\hline EDV (mL) & & & & & .0001 \\
\hline P-MVR $(n=15)$ & $145 \pm 57^{*}$ & $114 \pm 52$ & $112 \pm 41$ & .0001 & \\
\hline C-MVR $(\mathrm{n}=21)$ & $176 \pm 36^{*}$ & $118 \pm 24 \dagger$ & $107 \pm 28$ & .0001 & \\
\hline$P$ value (group) & .05 & .75 & .63 & & \\
\hline ESV $(\mathrm{mL})$ & & & & & .0001 \\
\hline P-MVR & $46 \pm 24$ & $56 \pm 31$ & $50 \pm 20$ & .09 & \\
\hline C-MVR & $60 \pm 13^{*}$ & $50 \pm 12 \dagger$ & $40 \pm 11$ & .0001 & \\
\hline$P$ value (group) & .03 & .45 & .06 & & \\
\hline ESS (kdyne/cm²) & & & & & .0001 \\
\hline P-MVR & $99 \pm 34$ & $99 \pm 29$ & $113 \pm 24$ & .07 & \\
\hline C-MVR & $120 \pm 19^{*}$ & $90 \pm 16 \dagger$ & $104 \pm 16$ & .0001 & \\
\hline$P$ value (group) & .02 & .24 & .21 & & \\
\hline LAFS $(\%)$ & & & & & .0001 \\
\hline P-MVR & $20 \pm 5^{*}$ & $12 \pm 4$ & $12 \pm 3$ & .0001 & \\
\hline C-MVR & $17 \pm 3$ & $14 \pm 2 \dagger \ddagger$ & $17 \pm 2$ & .0001 & \\
\hline$P$ value (group) & .07 & .02 & .0001 & & \\
\hline EF $(\%)$ & & & & & .0001 \\
\hline P-MVR & $70 \pm 12^{*}$ & $51 \pm 15$ & $56 \pm 6$ & .0001 & \\
\hline C-MVR & $64 \pm 8$ & $56 \pm 7 \dagger \ddagger$ & $63 \pm 4$ & .0001 & \\
\hline$P$ value (group) & .10 & .19 & .0007 & & \\
\hline $\operatorname{LVM}(\mathrm{g})$ & & & & & .0001 \\
\hline P-MVR & $206 \pm 76$ & $210 \pm 80$ & $192 \pm 63$ & .12 & \\
\hline C-MVR & $220 \pm 44$ & $234 \pm 49$ & $163 \pm 39 \S$ & .0001 & \\
\hline$P$ value (group) & .42 & .29 & .10 & & \\
\hline ESS/ESV (kdyne/cm²-mL) & & & & & .0002 \\
\hline P-MVR & $2.63 \pm 1.33$ & $2.24 \pm 1.27 \ddagger$ & $2.59 \pm 0.98$ & .02 & \\
\hline C-MVR & $2.07 \pm 0.43$ & $1.84 \pm 0.32$ & $2.78 \pm 0.72 \S$ & .0001 & \\
\hline$P$ value (group) & .08 & .17 & .51 & & \\
\hline
\end{tabular}

Values are means $\pm 1 \mathrm{SD}$.

$P$ value (time $\times$ group), influence of time and procedure type; $P$ value (time), changes with time in each group; $P$ value (group), intergroup differences.

${ }^{*} P<.05$ versus discharge and 1 year.

$\dagger P<.05$ versus 1 year.

$\ddagger P<.05$ versus before the operation.

$\S P<.05$ versus before the operation and discharge.

pected to observe a decrease in both ESS and ESV in the C-MVR cohort. These findings suggest that preserving all chordal structures results in more favorable LV geometry and, consequently, LV afterload. This, in turn, leads to greater ventricular remodeling, as supported by the fact that a larger reduction in LVM was seen after 1 year (26\% vs $4 \%$ ). In a prospective analysis of 14 patients undergoing MVR, Popovic and associates ${ }^{6}$ also noted a decrease in LVM index in patients who had complete chordal preservation compared with those with excision of both leaflets.

In this analysis EF and LAFS were used as measures of LV ejection performance. At discharge, EF and LAFS were lower than preoperative values in both groups, but the declines were less than one half as much in the C-MVR cohort (13\% vs $28 \%$ and $14 \%$ vs $38 \%$, respectively). The relative preservation of these parameters was likely the result of the complete maintenance of the papillary-annular continuity. This is supported by other studies $2,8,30,31$ demonstrating a reduction in fractional shortening in the LV regions subtended by the papillary muscles.
Nonetheless, it was still rather surprising to find the initial small decrease in EF and LAFS because others have reported no change in EF after chordal-sparing MVR. 1,2,4,7,25,27 However, EF is highly load dependent ${ }^{32}$ and a poor indicator of LV systolic function in patients with chronic mitral insufficiency caused by the imposed abnormal loading conditions. ${ }^{33}$ Because ESS decreased and the ESS/ESV ratio remained relatively unchanged in the CMVR group, the decreases in EF and LAFS were not due to augmented afterload or deterioration in LV function but rather to the greater abrupt fall in preload associated with correction of the volume overload situation. In contrast, the reduction in ESS/ESV in the P-MVR cohort suggests that a real decline in LV systolic performance was partly responsible for the decrease in EF and LAFS. Okita and colleagues $^{2}$ also noted higher ESS/ESV ratios in patients undergoing complete chordal-sparing MVR compared with those after conventional MVR. Whereas EF and LAFS returned to baseline values in the C-MVR group after 1 year, these parameters remained depressed in the P-MVR 


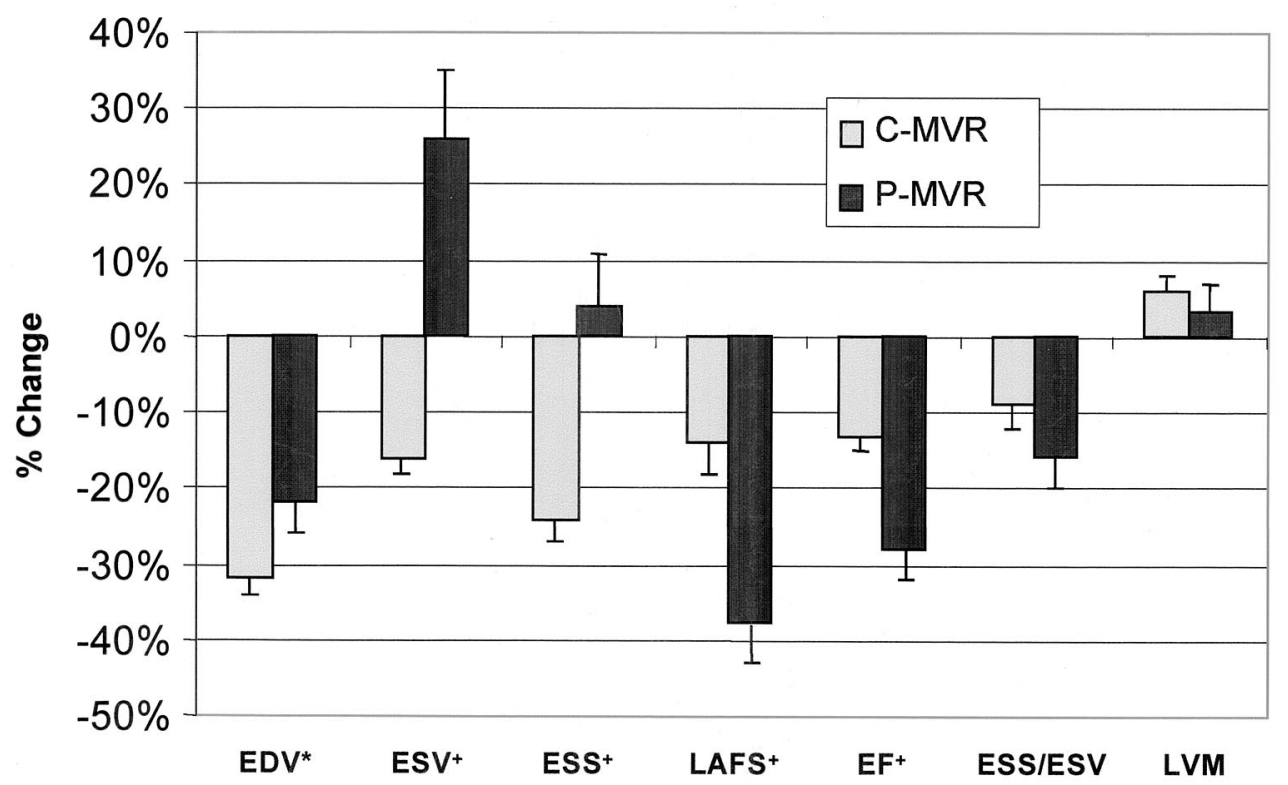

Figure 1. Percentage changes $( \pm$ SEM) in echocardiographic variables at discharge from preoperative level according to procedure type $\left({ }^{*} P=.009 ;+P<.001\right)$.

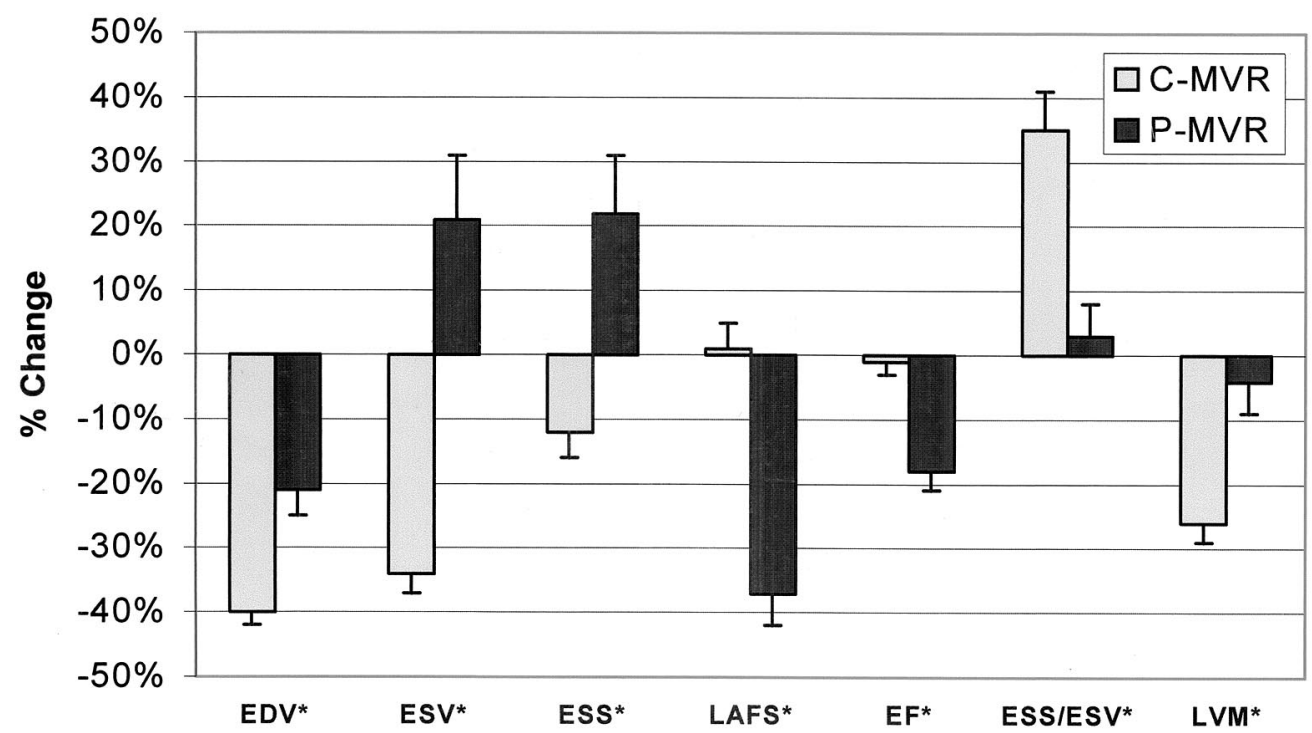

Figure 2. Percentage changes $( \pm$ SEM) in echocardiographic variables after 1 year from preoperative level according to procedure type $\left({ }^{*} P<.001\right)$.

cohort. Although the ESS/ESV ratio trended toward the preoperative value in those with posterior chordal preservation only, loading conditions became more unfavorable, as evident by the rise in ESS. On the other hand, even though ESS increased slightly by 1 year in the C-MVR group, a true improvement in LV systolic function was likely, as demonstrated by the $35 \%$ increase in the ESS/ESV ratio.

We are aware of only 4 other clinical investigations , $^{4,8,34}$ addressing the issue of C-MVR versus P-MVR in terms of
LV mechanics. Although the groups both at the National Institutes of Health ${ }^{4}$ and the Medical University of South Carolina $^{7}$ demonstrated the superiority of chordal-sparing MVR over conventional MVR, no significant differences were noted between patients receiving either posterior or bileaflet chordal preservation. However, the total number of patients in each study was relatively small (14 and 8, respectively) thereby reducing the likelihood of detecting a statistical difference. Similarly, Straub and associates ${ }^{34}$ re- 


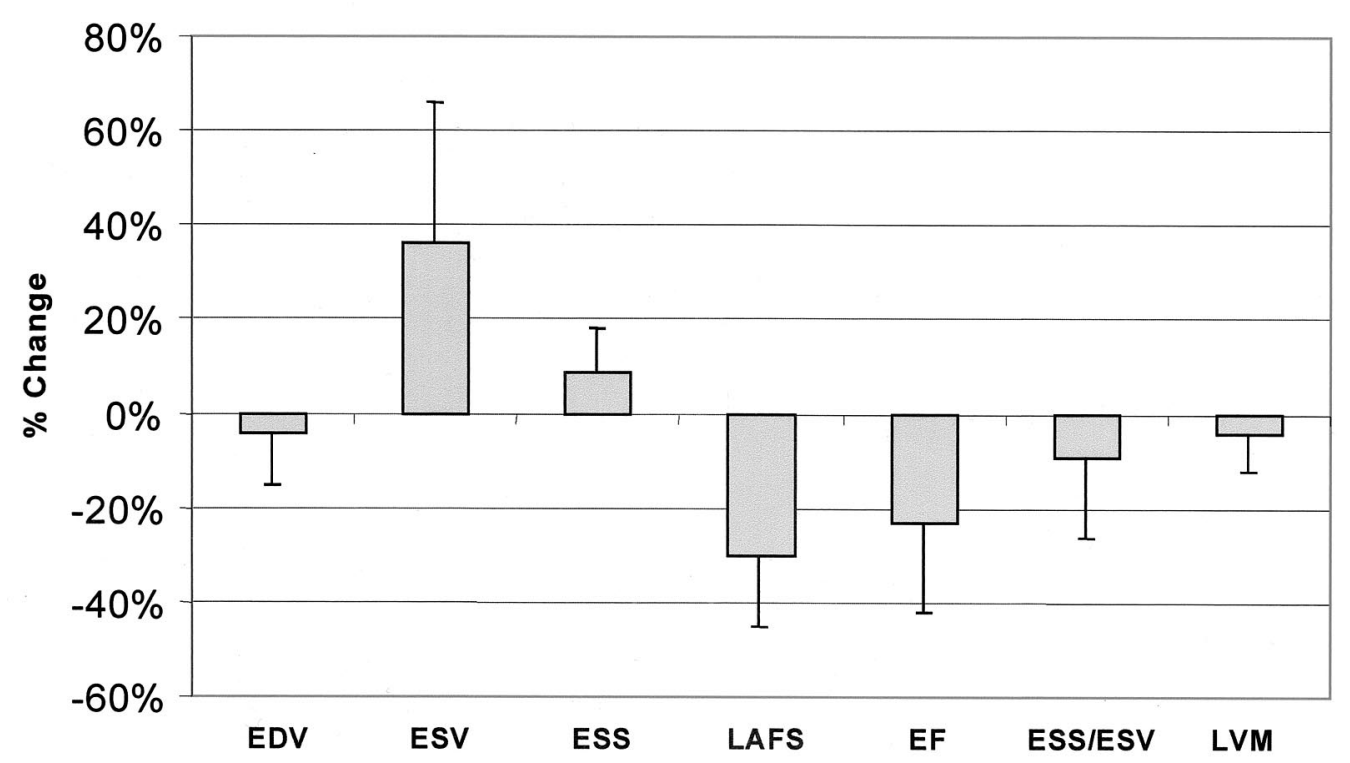

Figure 3. Percentage changes ( \pm SEM) in echocardiographic variables after 1 year from preoperative level in patients with a preoperative end-systolic dimension of greater than $50 \mathrm{~mm}$.

ported improved LV volumes and ejection performance with chordal preservation compared with resection at 3 months postoperatively. Although no differences were detected between partial versus complete chordal-sparing techniques, bileaflet retention resulted in relatively preserved regional wall motion. Furthermore, the analysis was complicated by the fact that $31 \%$ of patients in whom partial or complete chordal preservation was possible received additional aortic valve replacement. Lastly, in a study at the Saga Medical School in Japan, Natsuaki and colleagues ${ }^{8}$ retrospectively compared the effects of complete versus partial chordal-sparing MVR. Consistent with our findings, retaining all subvalvular structures resulted in declines in EDV and ESV, without a significant change in EF. Preserving only the posterior chords, on the other hand, was associated with a lower postoperative EF and a smaller decrease in ESV.

Several limitations of this study should be addressed. First, because data were not available for 7 patients as a result of loss to follow-up, perioperative death, and poorquality echocardiograms, the number of patients was smaller than anticipated. Consequently, the statistical power to detect differences among the cohorts was lower. Despite this shortcoming, significant improvements were noted with complete chordal preservation compared with partial retention.

Second, we do not have a good explanation for the differences in the preoperative parameters between the 2 groups other than small sample size. However, the selection bias would have been against the C-MVR group because these patients had larger preoperative EDV, ESV, and ESS values, as well as lower values of EF, LAFS, and ESS/ESV ratio. The fact that this cohort had superior LV mechanics, both immediately after MVR and at 1 year, provides further support for the importance of preserving all chordal structures.

Third, reading of the echocardiograms may not be totally blinded because it is possible to distinguish between complete and partial chordal preservation with detailed examination of the studies. However, all measurements were independently verified by a second echocardiographer who had no knowledge of the purpose of the study.

Finally, 4 patients in this study had preoperative LV end-systolic dimensions greater than $50 \mathrm{~mm}$. Their echocardiographic data were excluded from analysis to avoid a potential bias to the analysis. Indeed, as shown in Figure 3, LV volumes and systolic performance deteriorated at 1 year in this group of patients. Only one patient had improved hemodynamics, and this individual had all chordae tendineae retained. A repeat analysis of the data was performed to ensure the validity of our findings, which included these 4 patients. Although the statistical $P$ values changed slightly, the overall results of the study were relatively unaltered.

In conclusion, complete retention of the mitral subvalvular apparatus during MVR confers a significant early advantage by reducing LV chamber size and systolic afterload compared with that seen after partial chordal preservation. Furthermore, LV ejection performance continues to improve at 1 year as a result of improved remodeling. Therefore when MVR is necessary, we recommend that attempts should be made to preserve all chordal structures to 
optimize early postoperative and late LV systolic function. Additionally, a preoperative systolic diameter of $50 \mathrm{~mm}$ or greater may portend a poor prognosis.

\section{References}

1. David TE, Uden DE, Strauss HD. The importance of the mitral apparatus in left ventricular function after correction of mitral regurgitation. Circulation. 1983;68(Suppl):II-76-82.

2. Okita Y, Miki S, Ueda Y, Tahata T, Sakai T. Left ventricular function after mitral valve replacement with or without chordal preservation. J Heart Valve Dis. 1995;4(suppl II):S181-93.

3. Lee EM, Shapiro LM, Wells FC. Importance of subvalvular preservation and early operation in mitral valve surgery. Circulation. 1996; 94:2117-23.

4. Hannein HA, Swain JA, McIntosh CL, Bonow RO, Stone CD, Clark RE. Comparative assessment of chordal preservation versus chordal resection during mitral valve replacement. J Thorac Cardiovasc Surg. 1990;99:828-37.

5. Komeda M, David TE, Rao V, Sun Z, Weisel RD, Burns RJ. Late hemodynamic effects of the preserved papillary muscles during mitral valve replacement. Circulation. 1994;90(Suppl):II-190-4.

6. Popovic Z, Barac I, Jovic M, Panic G, Miric M, Bojic M. Ventricular performance following valve replacement for chronic mitral regurgitation: importance of chordal preservation. J Cardiovasc Surg (Torino). 1999;40:183-90.

7. Rozich JD, Carabello BA, Usher BW, Kratz JM, Bell AE, Zile MR. Mitral valve replacement with and without chordal preservation in patients with chronic regurgitation: mechanisms for differences in postoperative ejection performance. Circulation. 1992;86:1718-26.

8. Natsuaki M, Itoh T, Tomita S, Furukawa K, Yoshikai M, Suda H, et al. Importance of preserving the mitral subvalvular apparatus in mitral valve replacement. Ann Thorac Surg. 1996;61:585-90.

9. Come PC, Riley MF, Weintraub RM, Wei JY, Markis JE, Lorell BH, et al. Dynamic left ventricular outflow tract obstruction when the anterior leaflet is retained at prosthetic mitral valve replacement. Ann Thorac Surg. 1987;43:561-3.

10. Yun KL, Sintek CF, Miller DC, Schuyler GT, Fletcher AD, Pfeffer TA, et al. Randomized trial of partial versus complete chordal preservation methods of mitral valve replacement: a preliminary report. Circulation. 1999;100(Suppl):II-90-4.

11. Sintek CF, Pfeffer TA, Kochamba GS, Khonsari S. Mitral valve replacement: technique to preserve the subvalvular apparatus. Ann Thorac Surg. 1995;59:1027-9.

12. Mirsky I. Left ventricular stresses in the intact human heart. Biophys J. 1969;9:189-208.

13. Carabello BA, Nolan SP, McGuire LB. Assessment of preoperative left ventricular function in patients with mitral regurgitation: value of the end-systolic wall stress/end-systolic volume ratio. Circulation. 1981;64:1212-7.

14. Devereux RB, Reichek N. Echocardiographic determination of left ventricular mass in man: anatomic validation of the method. Circulation. 1977;55:613-8.

15. Schuler G, Peterson KL, Johnson A, Francis G, Dennish G, Utley J, et al. Temporal response of left ventricular performance to mitral valve surgery. Circulation. 1979;59:1218-31.

16. Borow KM, Green LH, Mann T, Sloss LJ, Braunwald E, Collins JJ, et al. End-systolic volume as a predictor of postoperative left ventricular performance in volume load from valvular regurgitation. Am J Med. 1980;68:655-63

17. Zile MR, Gaasch WH, Carroll JD, Levine HJ. Chronic mitral regurgitation: predictive value of preoperative echocardiographic indexes of left ventricular function and wall stress. J Am Coll Cardiol. 1984; 3:235-42.

18. Crawford MH, Souchek J, Oprian CA, Miller DC, Rahimtoola S, Giacomini JC, et al. Determinants of survival and left ventricular performance after mitral valve replacement. Circulation. 1990;81: $1173-81$.
19. Weisenbaugh T, Skudicky D, Sareli P. Prediction of outcome after valve replacement for rheumatic mitral regurgitation in the era of chordal preservation. Circulation. 1994;89:191-7.

20. Hansen DE, Cahill PD, Derby GC, Miller DC. Relative contributions of the anterior and posterior mitral chordae tendineae to canine global left ventricular systolic function. J Thorac Cardiovasc Surg. 1987;93: 45-55.

21. Yun KL, Fann JI, Rayhill SR, Nasserbakht F, Derby GC, Handen CE, et al. Importance of the mitral subvalvular apparatus for left ventricular segmental systolic mechanics. Circulation. 1990;82(Suppl):IV89-104.

22. Oe M, Asou T, Kawachi Y, Kishizaki K, Fukamachi K, Sunagawa K, et al. Effects of preserving mitral apparatus on ventricular systolic function in mitral valve operations in dogs. J Thorac Cardiovasc Surg. 1993;106:1138-46.

23. Boucher CA, Bingham JB, Osbakken MD, Okada RD, Stauss HW, Block PC, et al. Early changes in left ventricular size and function after correction of left ventricular volume overload. Am J Cardiol. 1981;47:991-1004.

24. Huikuri HV. Effect of mitral valve replacement on left ventricular function in mitral regurgitation. Br Heart J. 1983;49:328-33.

25. David TE, Burns RJ, Bacchus CM, Druck MN. Mitral valve replacement for mitral regurgitation with and without preservation of chordae tendineae. J Thorac Cardiovasc Surg. 1984;88:718-25.

26. Enriquez-Sarano M, Jajik AJ, Schaff HV, Orszulak TA, McGoon MD, Bailey KR, et al. Echocardiographic prediction of left ventricular function after correction of mitral regurgitation: results and clinical implications. J Am Coll Cardiol. 1994;24:1536-43.

27. Goldfine H, Aurigemma GP, Zile MR, Gaasch WH. Left ventricular length-force-shortening relations before and after surgical correction of chronic mitral regurgitation. J Am Coll Cardiol. 1998;31:180-5.

28. Straub UJ, Huwer H, Petzold T, Kalweit G, Volkmer I, Gams E. Preservation of the mitral subvalvular apparatus in multiple valve procedures. J Heart Valve Dis. 1995;4:477-83.

29. Goldfine H, Aurigemma GP, Zile MR, Gaasch WH. Left ventricular length-force-shortening relations before and after surgical correction of chronic mitral regurgitation. J Am Coll Cardiol. 1998;31:180-5.

30. Corin WJ, Sutsch G, Murakami T, Krogmann ON, Turina M, Hess OM. Left ventricular function in chronic mitral regurgitation: preoperative and postoperative comparison. J Am Coll Cardiol. 1995;25: 113-21.

31. Pitarys CJ II, Forman MB, Panayiotou H, Hansen DE. Long-term effects of excision of the mitral apparatus on global and regional ventricular function in humans. J Am Coll Cardiol. 1990;15:557-63.

32. DePace NL, Ren JG, Iskandrian AS, Kolter MN, Hakki AH, Segal BL. Correlation of echocardiographic wall stress and left ventricular pressure and function in aortic stenosis. Circulation. 1983;67:854-9.

33. Corin WJ, Monrad ES, Murakami T, Nonogi H, Hess OM, Krayenbuehl $\mathrm{H}$. The relationship of afterload to ejection performance in chronic mitral regurgitation. Circulation. 1987;76:59-67.

34. Straub UJ, Huwer H, Kalweit G, Wolkmer I, Gams E. Improved regional left ventricular performance in mitral valve replacement with orthotopic refixation of the anterior mitral leaflet. $J$ Heart Valve Dis. 1997;6:395-403.

\section{Discussion}

Dr Edward D. Verrier (Seattle, Wash). Thank you for the opportunity to discuss this interesting clinical study performed at Los Angeles Kaiser Permanente and analyzed at a number of prestigious institutions. Preliminary analysis of these data with similar conclusions was published in Circulation in 1999, although the 1-year follow-up data were not included. Dr Yun has done an excellent job presenting the data.

Over the past 20 years, we have certainly increased our understanding of the complex anatomic and physiologic functions of the mitral valve apparatus. Dr Craig Miller, one of the authors of this presentation and past president of the Western Thoracic Surgical 
Association, has contributed much to that basic understanding through elegant animal models.

One clear concept from that research that is applicable to MVR and based on extensive clinical experience with mitral valve repair techniques is the importance of preserving annular, chordal, and muscle continuity to preserve LV function. Surgeons, however, have been somewhat reluctant to adopt complete anterior and posterior chordal preservation in contrast to simply preserving the posterior leaflets because of the very real concerns of increased technical complexity, longer operating time, partial interference with mechanical valve leaflet motion, and the potential of creating LV outflow tract obstruction, particularly with very myxomatous valves, when leaving the anterior leaflet.

No previous prospective, randomized trial has compared complete versus partial or posterior preservation of the chordal apparatus during MVR. This is particularly important on the basis of the recent insights of the importance of the mitral apparatus on the hot topic of ventricular remodeling.

I have a few concerns and questions for the author. My first concern is that this is a single-institution, essentially single-surgeon study. Could there be a selection bias? The reason I ask is based on the following reasoning and observations. First, when you look at the echocardiographic results presented in the manuscript in Table 2, the complete versus the partial groups from baseline are really different. The preoperative EDV, ESV, ESS, LAFS, LVM, and ratio of stress to volume all have $P$ values of between .2 and .8. With such a small cohort size in each group, one greater or one fewer patient in either group could make a rather profound difference in the statistics. The overall ventricular size was larger in both diastole and systole in the complete chordalsparing group. Therefore might one not speculate a better functional echocardiographic result with any type of chordal sparing?

The second factor that may affect the conclusions on the basis of selection is that of the 47 patients initially entered into this study. Eleven, or $21 \%$, were excluded for a variety of reasons. This seems like a very high number. How was the randomization process done? Why were the initial ventricular volumes so different? And do you think that it would be worthwhile to perform a multi-institutional trial, or are you confident that there was no selection bias?

Dr Yun. To answer your question, the randomization was computer generated. We really have no good explanation for the differences in the preoperative parameters between the 2 groups other than perhaps small sample size. We agree that a multiinstitutional trial is worthwhile to confirm our findings. However, we are confident that there was no selection bias because all patients were randomized, and all data were analyzed and independently verified at the end of the study. Any selection bias would have been against the complete chordal-sparing group given the larger ventricular volume and poor ejection performance preoper- atively. The fact that this cohort performed better, both early and late, provides further support to the importance of retaining the whole mitral subvalvular apparatus.

Dr Verrier. My second question relates to the overall philosophy of repair versus replacement. Most surgeons report an approximate $85 \%$ chance of repairing a regurgitant mitral valve, particularly if myxomatous. For one institution to accumulate 47 patients over a 2-year period, that would roughly equate to over 312 patients operated on for mitral regurgitation and probably more because all patients with mitral stenosis or concomitant coronary artery disease were excluded. Why were so many MVRs done, or do you now believe that MVR with complete chordal preservation is superior to mitral valve repair?

Dr Yun. No, we do not believe that. We continue to advocate mitral repair as the first option because of the overwhelming data supporting mitral reconstruction in terms of LV systolic performance, including our previously published preliminary report. Although MVR with complete chordal preservation may have the same hemodynamic advantages, other beneficial effects of repair in terms of avoiding prosthetic valve-related complications have been demonstrated. I do not have the exact numbers, but over a 2-year span at our institution, approximately 5000 pump cases are performed, of which about 250, or 5\%, involved MVR for mitral regurgitation. However, I must admit that our repair rate is likely to be lower because of the fact that we are less tolerant of residual mitral regurgitation compared with other, larger institutions.

Dr Verrier. My final question is related to the analysis of the data. In the manuscript you stated that the echocardiograms were read blindly. I have asked my senior echocardiographers at the University of Washington whether they could recognize preserved anterior or posterior chords after MVR. Although shadowing can be a factor in transthoracic echoes, in most instances they thought they could see the subchordal apparatus. Because this is primarily an echocardiographic study, this concept seems important. How could the echocardiographer be blinded at the time of the study if they can see the chords, and could such knowledge then affect the subsequent measurements, interpretation, or both? Might this also be important because the authors carefully evaluated and previously published results with an $\mathrm{n}$ of 19 with the same conclusions as in this study? Were the echocardiograms truly blinded?

Overall, I believe this prospective design and the clear conclusions have important implications for the practicing cardiothoracic surgeon. Thank you for the opportunity to discuss.

Dr Yun. Dr Zile, our echocardiographer, assures me that, given the echogenicity of the mitral prosthesis, it is not a simple task to distinguish between complete versus partial chordal preservation without a detailed survey of the echocardiogram. Furthermore, all measurements were independently verified by a second echocardiographer who had no knowledge of the purpose of the study. 